\title{
Building the case for direct infrastructure
}

Received (in revised form): 20th March, 2008

\section{Danny Latham}

is Head of Infrastructure Investments, Europe, First State Investments. He is a pioneer of the infrastructure funds management industry, having been acquiring and managing infrastructure assets for the last 14 years. He currently has overall responsibility for First State's European infrastructure business and is fund manager of their European Infrastructure fund. He previously spent three years at RREEF Infrastructure, and was a founding member of the AMP Group's infrastructure team in 1994.

\begin{abstract}
Falling equity markets and a re-rating of credit markets in an inflationary environment are prompting many pension fund managers to reassess their strategic asset allocations. Moreover, a tactical overweight to alternatives may support investment performance at a time of increased uncertainty in listed markets. For some, investment allocation decisions made now may prove to be the most significant for risk-adjusted returns since those made following the 2000 equity market downturn. What role can unlisted infrastructure investments play within a pension fund investment portfolio and why does it make particular sense to include them now?
\end{abstract}

Pensions (2008) 13, 83-87. doi:10.1057/pm.2008.8

Keywords: infrastructure, investment, asset class, direct infrastructure, infrastructure fund, asset allocation

\section{Introduction}

Sophisticated institutional investors are well versed in the key characteristics/benefits of infrastructure investments. Infrastructure businesses are capable of generating long-term, stable and predictable cash flows and these cash flows are often explicitly or implicitly inflation protected which has significant appeal in the current volatile and potentially inflationary investment environment.

The three primary reasons why infrastructure investment cash flows are typically stable and predictable include the stage of development of the asset, the inelastic demand of the service it provides and the typical lack of competition it faces.

\section{Stage of development}

The point at which an investment is made in an infrastructure business is the foundation of its

Correspondence: Danny Latham, First State Investments, UK

E-mail: dlatham@firststate.co.uk achievable risk-adjusted return profile. The early phase is typically the riskiest period for infrastructure investments due to construction and completion risk, regulatory risk and patronage or traffic risk.

During the construction and development stages, the asset is typically not generating income so the motivation for investing at this time is to earn a risk premium on the capital component. As the business matures, the risks associated with the development of the asset reduce as shown in Figure 1.

By the time the asset is mature, the infrastructure business is capable of delivering steady, predictable income returns. These are often backed by long-term supply agreements or regulated revenues. At this stage, the risk and return characteristics of the business are well suited to the long-term liabilities of pension funds.

\section{Demand elasticity}

Demand for the services of infrastructure

businesses is relatively inelastic because of the 
essential nature of those services. For example, rising fuel prices do not tend to materially affect the use of toll roads, and the stock market correction has not materially affected people's ability to pay their electricity or water bills. In fact, the only infrastructure sectors that are significantly exposed to cyclicality are airports and ports and long-term investors tend to overcome this issue by investing for at least one cycle.

One obstacle we have seen is centred around the supply of money being greater than the supply of assets in circulation. In the short term this could affect the expected returns to be generated. We expect the supply/demand balance to reach equilibrium in the medium term; however, scarcity of supply of assets in the short term means risk-adjusted returns could

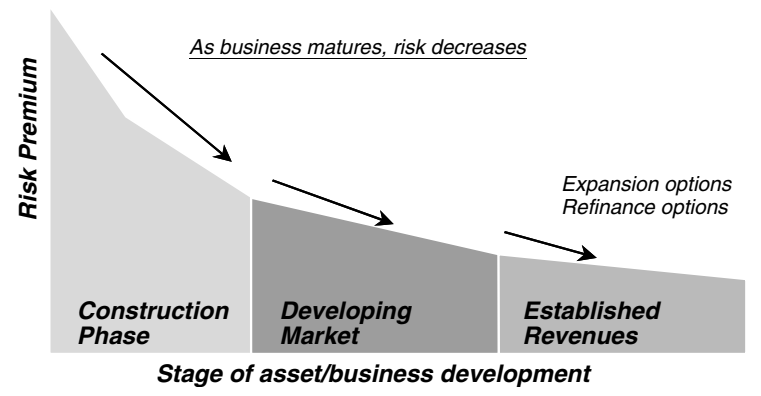

Figure 1: Risk evolution of infrastructure investments Source: CFS GAM. Source date: February 2008. move down more quickly than previously anticipated.

Figure 2 indicates the categories of infrastructure sectors. Removing airports and ports, there are a lot of categories that are not subject to significant cyclicality.

\section{Lack of competition - Barriers to entry}

The typical lack of competition that most infrastructure companies face means they enjoy market dominance. This is often because of barriers to entry for any aspiring competitors.

For example, it is easy to imagine the cost of constructing a new airport or port as being prohibitive, especially when it is in the same geographic region as existing port services. The distribution of water and gas is also typically bound by regional borders due to the investment in significant pipeline infrastructure required to deliver these commodities to the end customer.

\section{Portfolio application}

An insight into the portfolio benefit of including unlisted infrastructure in a balanced portfolio can be gained by examining return correlations with other asset classes. Figure 3 shows that the rolling five-year correlation between monthly returns of Australian unlisted infrastructure and equities has been decreasing until June 2007 when there was

\begin{tabular}{|c|c|c|c|c|}
\hline \multicolumn{4}{|c|}{ Economic Infrastructure } & \multirow{2}{*}{$\begin{array}{c}\text { Social } \\
\text { Infrastructure }\end{array}$} \\
\hline Transport & $\begin{array}{c}\text { Energy \& } \\
\text { Utilities }\end{array}$ & $\begin{array}{l}\text { Communi- } \\
\text { cations }\end{array}$ & Other & \\
\hline 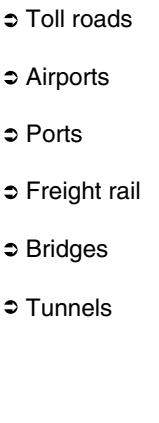 & $\begin{array}{l}\text { จ Gas } \\
\text { - Distribution } \\
\text { - Transmission } \\
\text { o Electricity } \\
\text { - Distribution } \\
\text { - Transmission } \\
\text { - Generation } \\
\text { o Renewable } \\
\text { energy } \\
\text { o Water }\end{array}$ & $\begin{array}{l}\text { Cable } \\
\text { networks } \\
\text { o Satellite } \\
\text { systems } \\
\text { क Mobile } \\
\text { towers }\end{array}$ & $\begin{array}{l}\rightarrow \text { Forests } \\
\text { Car parks } \\
\text { Ferry } \\
\quad \text { operators }\end{array}$ & 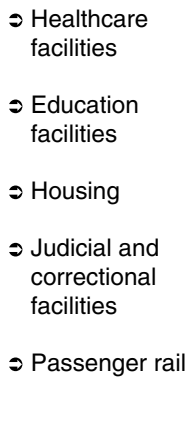 \\
\hline
\end{tabular}

Figure 2: Source CFS Research. Source date: February 2008. 


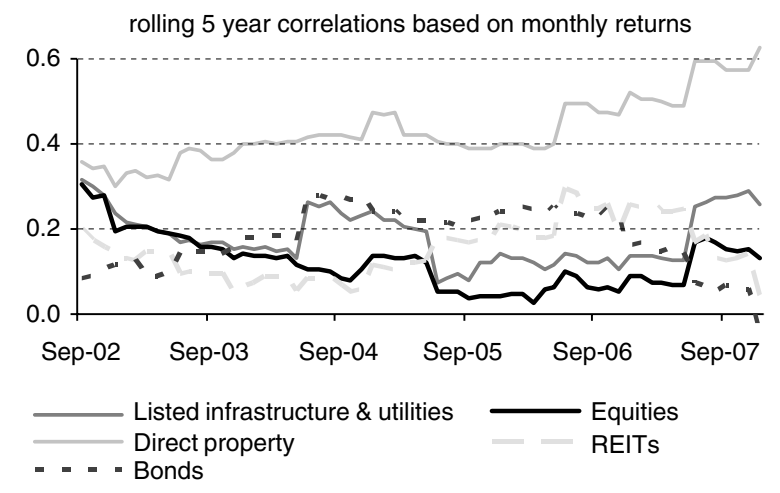

Figure 3: Return correlation: Unlisted infrastructure to other Australian asset classes

Source: CFS Research. Source date: February 2008.

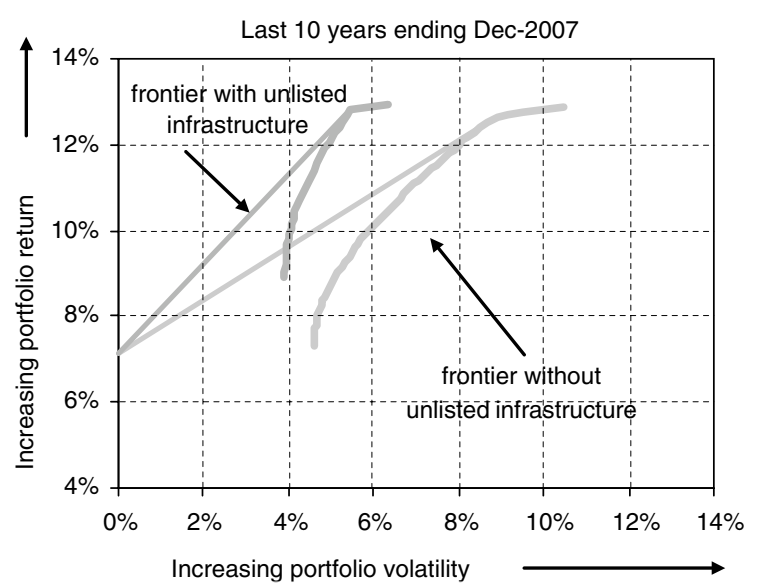

Figure 4: Efficient portfolio frontier Source: CFS Research. Source date: February 2008.

a notable upturn. This upturn was evident for the correlations of unlisted infrastructure with listed infrastructure, with equities and with direct property. This rise in correlation reflects the recent drop in performance across these asset classes as correlations tends to rise when markets jointly fall.

The diversification benefits of including unlisted infrastructure in a balanced portfolio are further illustrated in Figure 4. This chart compares a portfolio of six asset classes including unlisted Australian infrastructure, Australian equities, Australian fixed interest, Australian listed property trusts, overseas fixed interest and overseas equities, with a portfolio of five assets, that is, excluding unlisted infrastructure. The efficient frontier is superior for the portfolio that includes unlisted infrastructure. NB. Australian data are used because it is the only region where unlisted infrastructure return series are publicly available.

\section{Ongoing benefits}

For those without an allocation to unlisted infrastructure its performance history speaks for itself; however the big question is: will it continue to remain attractive?

There are several characteristics that suggest wholesale infrastructure will continue to offer an important role in pension portfolios.

These include the defensive nature of the investment in the current volatile environment, the ability to actively manage risks, the growing government support for private sector involvement, the maturation of the investment sector and the diversification benefits.

\section{Credit market crisis}

The defensive nature of infrastructure assets makes them an attractive credit risk compared with other sectors. Those with stable or regulated returns are likely to weather the current credit risk re-pricing well and are expected to attract fixed interest investors seeking a flight to quality. Figure 5 shows the increase in spreads for European utilities and energy companies since the beginning of the risk-repricing period was the smallest after senior bank debt.

\section{Risk management}

The chief caveat regarding the defensive quality of infrastructure investments is that not all infrastructure is a safe haven during periods of high market volatility. There is a clear need for risks to be well managed.

This is where 'active management' of such an asset cannot be understated. This involves shareholders influencing management via Board representation to improve firm performance for the benefit of the investors. Such areas include being able to work closely with management to define and implement strategy including the 


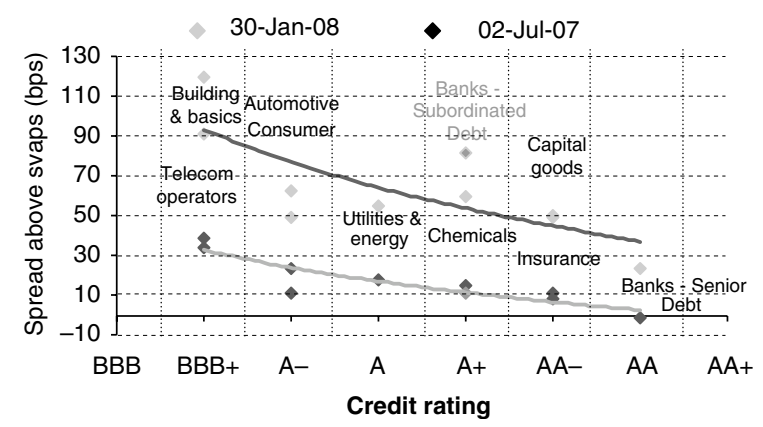

Figure 5: Spread level above swap rates vs rating by industry

Source: Fortis Credit Research \& CFS Research. NB: Subordinated bank debt is highlighted in orange as it has experienced the greatest increase in swap spreads over the period. Source date: February 2008.

setting of financing, operating and dividend policies. This level of control is therefore a method of reducing investment risk by helping to ensure long-term performance targets are met.

This requirement helps explain the growing number of specialised infrastructure investors with the expertise to actively manage the risks of such assets on behalf of their clients.

\section{Government motivation}

Governments are particularly motivated to create a strong infrastructure network. This is because a country's infrastructure is the platform on which living standards and economic growth is made possible.

A shortage of electricity, roads, rail, airports, ports, utilities and water treatment plants will eventually constrain a country's expansion, not to mention the impact on the living standards of its population.

Where there are no substitutes for a particular infrastructure service, the consequences can affect economic growth. An example of this economic impact is the power shortages suffered in China during devastating snowstorms at the end of January this year.

These shortages hindered the production of steel. It is therefore in the interests of policy makers to ensure infrastructure services are relevant, reliable and predictable.

The problem is that many governments are cutting their infrastructure spend or are funding the upkeep and construction of infrastructure using public sector debt. A favourable option for many of these governments is to turn to private sector funding and expertise. This will only be achieved if infrastructure transactions are commercially attractive.

There has been a lot of money mobilised towards the direct infrastructure sector over the last 12-18 months. As a result there have been some concerns raised recently around the level of dealflow and associated pricing. On the downside, prevailing economic uncertainty and associated job security has also resulted in increased concerns by government in either private participation in, or foreign ownership of, key infrastructure assets. An example of this was the requirement of the US government for $\mathrm{D} P$ World to divest the US portion of the $\mathrm{P} \& \mathrm{O}$ Ports portfolio which was acquired in 2006. This emerging theme is expected to reduce asset supply in the short term, however in the medium term such concerns are expected to dissipate.

\section{Maturing market}

The global infrastructure investment market is maturing quickly, but still remains an embryonic, evolving industry where there may be some degree of divergence of returns. Although on the whole the direct infrastructure asset class is one of low volatility, one caveat to note is that there may be some element of discrepancy in the distribution of returns, compared to a more mature sector.

On the other hand with every deal, sellers and buyers build a greater understanding of the assets and their expected return characteristics. The number of investors seeking exposure to the asset class has seen a structural increase and this has resulted in an explosion of infrastructure investment offerings.

Current return expectations for global mature infrastructure are estimated to be in the range of 8-12 per cent p.a.

\section{Diversification benefits}

The diversification properties of wholesale infrastructure investments are expected to remain intact. This is because the investment 
characteristics of unlisted infrastructure are sufficiently different from other asset classes.

\section{Conclusion}

The US sub-prime mortgage crisis has sparked investment market volatility that has seen a global move to investments with defensive qualities. Mature-stage infrastructure fits this requirement due to its inelastic demand and high barriers to entry. These qualities make it an attractive yield play for pension funds seeking investments to match their long-term liabilities.

Historical correlations and risk-return profiles provide a strong case for the portfolio diversification that can be achieved with the inclusion of wholesale infrastructure investments in a pension fund. The differentiation with other asset classes should mean that this diversification benefit exists in the future. Interest in the sector is also expected to be supported by investors seeking stability in the current volatile environment, the attraction of being able to actively manage risks within infrastructure investments, the growing government support for private sector involvement as well as the maturation of the sector.

The downturn in equity markets is a cyclical event rather than a structural one. The question of whether strategic allocations to infrastructure should now be adjusted depends largely on the long-term risk and return projections that were factored into asset allocation models following the tech bubble.

Assuming the long-term return outlook remains relatively unchanged, there is little reason to adjust over-allocations to infrastructure as a result of a fall in equity markets.

A tactical tilt to more defensive assets such as unlisted infrastructure is likely to help mitigate current equity market volatility.

The big caveat for all these benefits of wholesale infrastructure investments is that risks need to be actively managed. This requires expertise and experience in ensuring the investment is managed to the benefit of investors.

(C) First State Investments 